\title{
An integrated approach for supply chain assessment from resilience engineering and ergonomics perspectives
}

\author{
Mohsen Sadegh Amalnick ${ }^{a}$ and Mohammad Mahdi Saffar ${ }^{a^{*}}$
}

${ }^{a}$ School of Industrial Engineering, College of Engineering, University of Tehran, Tehran, Iran

\begin{tabular}{l}
\hline C H R O N I C L E \\
\hline Article history: \\
Received December 2, 2016 \\
Received in revised format \\
December 10, 2016 \\
Accepted February 172017 \\
Available online \\
February 172017 \\
\hline Keywords: \\
Aerospace supply chain \\
Data envelopment analysis \\
(DEA) \\
Ergonomics \\
Resilience Engineering
\end{tabular}

\section{Introduction}

Supply chain management comprises managing production and supply procedures by considering the whole supply chain network from the beginning to the end of the product lifecycle. In recent years, organizations compete in an expanded competitive area due to the advancement in connection. Thus, designing and using supply chain networks in an economic manner have become more important. In this competitive business atmosphere, organizations' success depends on being aware of their strengths and weaknesses to perform continuous improvement programs. Therefore, a comprehensive assessment approach is required to achieve a precise image of organization. Supplier selection as a multi-criteria decision making problem plays a significant role in supply chain management success. According to its importance, several approaches have been proposed to solve supplier selection problem (Roshandel et al., 2013; Yazdani, 2014; Awasthi et al., 2010; Burtscher \& Manser, 2012).

\footnotetext{
* Corresponding author Tel: +989122939830

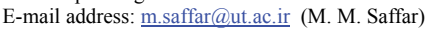

(C) 2017 Growing Science Ltd. All rights reserved. doi: $10.5267 /$ j.uscm.2017.2.001
} 
The role of human factor in complex systems, such as supply chain management (SCM), is inevitable (Hale \& Hovden, 1998; Kim, 2005; Paille \& Boiral, 2013; Clegg, 2000; Serdarasan, 2013). Khan et al. (2014) presented an integrated mathematical model taking into account human errors. Barnes and Liao (2012) studied the effect of individuals and network in SCM by considering human resource management. Human resources and other aspects of supply chain (SC) was investigated by Fung and Chen (2010), Koulikoff-Souviron and Harrison (2006), and Harrison (1999). Ergonomics plays an important role to keep workers in optimum condition, allowing for the adequate flow of materials and information (Vink, 2006). Ergonomics in supply chain has not received enough attention. Sinclair et al. (1995) discussed some of the ergonomics issues involved in simultaneous engineering from supply chains viewpoint. Azadeh et al. (2016) presented an integrated approach for examining the impact of macro-ergonomics factors in healthcare supply chain. The most effective macro-ergonomics factor is identified as "teamwork" issue.

Resilience supply chain is a provision to reduce customer perception of risks, however, there is no consensus on the definition of resilience (Elleuch et al., 2016). The idea has motivated researchers and experts to explore the concept of resilience engineering and its applications in the field of supply chain. Ponis and Koronis (2012) examined resilience in various fields including ecology, psychology, organization, and supply chains. Pettit et al. (2013) referred to ecology, psychology, sociology, risk management, and network theory to define resilience in supply chains. Ponomarov and Holcomb (2009) presented an integrated perspective on resilience through an extensive review of the literature in a number of disciplines including developmental psychology and ecosystems. It is concluded that the key elements of supply chain resilience and the relationships among them, the links between risks and implications for supply chain management, and the methodologies for managing these key issues are poorly understood. Kim et al. (2015) conceptualized supply network disruption and resilience by analyzing the structural relationships among different entities in the network. They compared four fundamental supply network structures and according to the results, resilience improves when the structural relationships in a network follow the power-law. Cardoso et al. (2015) considered eleven indicators to assess the supply chains' resilience, which comprise network design, centralization and operational indicators. The goal was to provide managers what are expected operational impacts (measured by the operational indicators) by assessing the behavior of network and centralization indicators and their known resilience behaviors from the literature. Supply chain plays a vital role in aerospace and aviation industries, and therefore it has been considered from different points of view. Sinha et al. (2004) presented a generic prescriptive methodology for mitigating risks in an aerospace supply chain. The methodology provided a mechanism to minimize conflicting objectives. Emiliani (2004) discussed the use of online reverse auctions to source engineered components in global aerospace supply chains using online reverse auctions. Ziaei and Sadegh Amalnick (2016) studied three main aspects of aerospace supply chain disruption, which are "outsourcing and partnership", "limited buffers" and "poor planning and execution". Then aspects of these causes as well as related solutions for each one of them are explained.

According to the literature review, supply chain evaluation by incorporating ergonomics and resilience engineering factors has not been considered. In this study, an integrated approach is proposed for analyzing the impact of resilience engineering and ergonomics in aerospace supply chain management. It is shown how data envelopment analysis (DEA) enables decision makers to investigate multiple output/input in order to analysis supply chain performance and also identify factors significance. In order to investigate the applicability of the proposed approach, 22 suppliers of aerospace industry are taken into account as decision making units (DMUs). Cost, lead time, delay and backlog depth are considered as inputs whilst service level, resilience engineering and ergonomics factors are considered as outputs. In the following sections, resilience engineering and ergonomics are briefly presented.

\subsection{Resilience engineering}

Resilience engineering (RE) is trying to increase the ability to create processes that are robust and flexible to modify and monitor risk models. RE uses resources proactively in spite of interruptions or 
economic and production stresses (Hollnagel et al., 2008). RE is the inherent ability of a system to continue its operations after a major disaster or in the presence of operational stresses. In this context, safety is defined as the capability of a company to succeed under unpredictable conditions. RE attempts to manage and understand everyday functioning to understand safety performance of a company (Woods \& Hollnagel, 2006). In a resilient system, ten main items have been identified from the literature that can be defined as follows (Hollnagel et al., 2007; Azadeh et al., 2014)

- Top management commitment (TMC): Management's commitment to invest and allocate resources to improve RE.

- Reporting culture (RC): The degree of encouraging reporting of improprieties, including safety problems and concerns of human resource.

- Preparedness (PR): Plans and policies for handling and managing before and during disasters.

- Flexibility (FL): Ability of a system to cope with complicated or new situation without needing to wait for management advices.

- Redundancy (RD): Doubling of essential human resource or components to increase system dependability.

\subsection{Macro-Ergonomics}

Human factors are generally categorized into two domains including micro-ergonomics and macroergonomics. In this study, the most important and relevant macro-ergonomics factors are taken into account (Azadeh et al., 2014; Jahanshahloo et al., 2005). Knowledge about situation assessment (situation analysis), human resource management culture, reliability and availability are selected as outputs.

\section{Methodology}

The proposed approach of this study for performance assessment of SCM systems and analyzing impact of presented factors is presented in Fig. 1 and described as follows:



Fig. 1. Structure of the proposed approach 
First of all, quantitative factors including cost, delivery time, delay, backlog, service level, availability and reliability are obtained from historical data. Related data for qualitative factors been gathered by questionnaire. Respondents must assign a number between 1 and 10 to each question (from 1: very low to 10: very high). Reliability of questionnaires is tested via Cronbach's alpha by using SPSS ${ }^{\circledR}$. Inputs and outputs of DEA are identified and the preferred DEA model, among four input /output and VRS/CRS models, is selected based on maximum average efficiency. Based on the selected DEA model, efficiency scores of DMUs are calculated and the most efficient one is identified. Furthermore, sensitivity analysis is performed to identify the most important factors by applying DEA. The most influential factors are identified according to the greatest change by removing them are made to the efficiency scores. Finally, the average potential for improving the supply chain parameters is measured using average value of measured data and average value of calculated target value from the DEA model.

\subsection{Data envelopment analysis (DEA)}

DEA is a non-parametric model that has been introduced by Charnes et al. (1978) and Banker et al. (1984). DEA simplify the comparison of different DMUs by constructing a single efficiency score for each unit by handling multiple outputs and inputs. The outputs and inputs might be in different dimensions. However a priori knowledge of weights of outputs and inputs is not required, managerial preferences can be applied when it is desired (Azadeh et al., 2013). DEA identifies efficient and inefficient units to help decision makers for continuous performance assessment and improvement of their systems. According to the mathematical model proposed by Charnes et al. (1978), the frontier generated by the method is a surface that follows the most efficient performers and shows the maximum combination of outputs obtained from a given level of inputs. Fig. 2 shows the empirical frontier created by DEA approach. It should be noted that the distance between each DMU's indicator and the efficient frontier is called slack. Decision makers provide improvement solutions to alleviate these slacks in order to reach the efficient frontier.

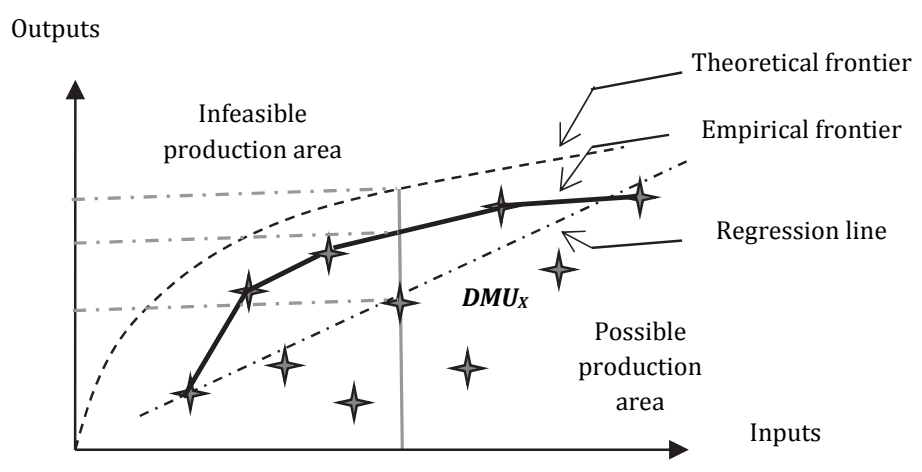

Fig. 2. Empirical and theoretical frontier.

In this paper, four well-known DEA models including constant returns to scale (CRS) and variable returns to scale (VRS) are applied (Charnes et al., 1978; Banker et al., 1984). Input and output oriented VRS and CRS model are developed and compared to find the preferred model for evaluating and ranking DMUs.

\section{Case study}

Aerospace supply chain is becoming more complex as airlines are expanding their fleets' size and at the same time aged equipment must be replaced. Safety management and human resources have important roles in this industry. In this study, Iranian civil aviation organization is considered as a case study to access 22 suppliers that provide spare parts and services to the domestic airlines. After specification of four inputs and 13 outputs, the next step is data collection for 22 suppliers which is 
shown in Table 1. Required data for quantitative factors (cost, lead time, delay, backlog, service level, availability and reliability) are gathered from historical data. For qualitative factors standard questionnaires are designed and the managers and experts have completed them.

Table 1

Row data for factors for suppliers

\begin{tabular}{|c|c|c|c|c|c|c|c|c|c|c|c|c|c|c|}
\hline DMU & $\mathbf{X}_{1}$ & $\mathbf{X}_{2}$ & $\mathbf{X}_{3}$ & $\mathbf{X}_{4}$ & $\mathbf{Y}_{1}$ & $Y_{2}$ & $Y_{3}$ & $Y_{4}$ & $Y_{5}$ & $Y_{6}$ & $Y_{7}$ & $Y_{8}$ & $Y_{9}$ & $Y_{10}$ \\
\hline 1 & 19.3 & 83.1 & 8.5 & 0.89 & 9.74 & 7.93 & 8.40 & 8.00 & 8.60 & 9.33 & 9.45 & 8.49 & 6.23 & 6.03 \\
\hline 2 & 34.1 & 83.5 & 6.2 & 0.88 & 8.86 & 7.98 & 8.05 & 8.68 & 7.04 & 7.05 & 6.09 & 7.60 & 9.02 & 8.47 \\
\hline 3 & 15.0 & 88.2 & 7.8 & 0.90 & 7.79 & 9.10 & 7.35 & 9.65 & 8.76 & 7.96 & 9.51 & 6.98 & 8.74 & 9.37 \\
\hline 4 & 21.9 & 99.5 & 11.4 & 1.00 & 9.03 & 7.76 & 8.70 & 8.87 & 9.30 & 7.90 & 7.90 & 7.62 & 9.80 & 9.91 \\
\hline 5 & 24.9 & 91.0 & 8.3 & 0.87 & 8.41 & 7.98 & 7.80 & 8.02 & 7.32 & 6.56 & 7.43 & 9.82 & 7.24 & 7.32 \\
\hline 6 & 22.8 & 79.0 & 18.4 & 1.00 & 8.00 & 8.00 & 7.60 & 7.56 & 8.01 & 8.08 & 7.73 & 9.66 & 9.21 & 9.98 \\
\hline 7 & 25.9 & 81.7 & 8.5 & 0.96 & 8.85 & 7.83 & 7.90 & 7.33 & 8.01 & 8.67 & 8.53 & 8.72 & 8.00 & 8.31 \\
\hline 8 & 24.3 & 87.2 & 11.3 & 0.89 & 9.74 & 7.93 & 8.30 & 9.34 & 7.93 & 8.67 & 8.25 & 8.49 & 6.23 & 6.03 \\
\hline 9 & 27.9 & 82.4 & 9.8 & 0.88 & 8.86 & 7.98 & 6.78 & 9.57 & 8.40 & 9.32 & 9.25 & 7.60 & 9.02 & 8.47 \\
\hline 10 & 29.4 & 81.9 & 7.7 & 0.79 & 8.75 & 9.10 & 6.99 & 8.67 & 8.00 & 7.67 & 8.10 & 6.98 & 8.74 & 9.37 \\
\hline 11 & 23.1 & 82.1 & 6.4 & 0.87 & 8.75 & 7.00 & 8.90 & 8.34 & 6.78 & 8.00 & 7.30 & 8.75 & 7.00 & 8.90 \\
\hline 12 & 28.6 & 83.1 & 8.1 & 0.86 & 8.23 & 6.50 & 8.75 & 8.33 & 8.80 & 8.00 & 8.50 & 8.43 & 7.83 & 8.00 \\
\hline 13 & 26.7 & 72.0 & 9.2 & 1.00 & 8.80 & 8.04 & 8.30 & 8.59 & 8.60 & 7.84 & 6.50 & 7.92 & 10.0 & 9.57 \\
\hline 14 & 27.2 & 79.9 & 8.6 & 0.89 & 8.75 & 9.45 & 8.25 & 7.67 & 7.20 & 8.45 & 8.91 & 7.55 & 7.82 & 8.89 \\
\hline 15 & 25.5 & 88.6 & 9.2 & 0.95 & 8.50 & 7.00 & 8.50 & 9.20 & 7.50 & 8.33 & 9.12 & 9.77 & 8.40 & 9.76 \\
\hline 16 & 21.9 & 86.6 & 7.8 & 0.91 & 9.25 & 9.35 & 8.25 & 9.30 & 8.00 & 9.67 & 7.73 & 7.72 & 7.45 & 8.75 \\
\hline 17 & 21.9 & 84.0 & 7.1 & 0.95 & 9.25 & 6.50 & 8.25 & 8.33 & 8.60 & 8.67 & 7.04 & 9.01 & 7.06 & 8.03 \\
\hline 18 & 20.8 & 78.4 & 6.7 & 0.90 & 8.50 & 7.00 & 8.25 & 8.33 & 8.42 & 8.67 & 8.25 & 8.56 & 7.55 & 8.71 \\
\hline 19 & 21.3 & 83.8 & 7.0 & 0.83 & 8.75 & 9.60 & 8.25 & 8.94 & 8.32 & 8.50 & 7.25 & 8.43 & 7.50 & 9.25 \\
\hline 20 & 22.7 & 82.2 & 9.1 & 1.00 & 8.89 & 7.12 & 8.39 & 8.44 & 8.23 & 8.18 & 8.50 & 7.92 & 6.00 & 8.50 \\
\hline 21 & 29.8 & 87.7 & 7.2 & 0.80 & 8.33 & 7.83 & 6.28 & 8.98 & 6.78 & 8.38 & 9.29 & 7.55 & 8.92 & 9.20 \\
\hline 22 & 24.4 & 85.0 & 8.3 & 0.98 & 8.45 & 9.03 & 9.49 & 9.04 & 6.77 & 9.34 & 9.26 & 9.77 & 8.50 & 8.75 \\
\hline
\end{tabular}

In order to test the reliability of the questionnaires, as mentioned before, the Cronbach's alpha for each qualitative factor is calculated. The results of the reliability test as well as some descriptive statistics are reported in Table 2.

Table 2

Descriptive statistics and Cronbach's alpha

\begin{tabular}{llll}
\hline Item & Average & St. D. & Cronbach's alpha \\
\hline Top management commitment & 8.00 & 1.68 & 0.92 \\
Reporting culture & 8.07 & 1.71 & 0.89 \\
Preparedness & 8.59 & 2.31 & 0.75 \\
Flexibility & 7.97 & 1.74 & 0.88 \\
Awareness & 8.32 & 1.83 & 0.91 \\
Redundancy & 8.17 & 1.95 & 0.81 \\
Human resource management & 8.33 & 2.45 & 0.76 \\
\hline
\end{tabular}

Based on the results, all factors had acceptable reliability levels, which is equal or greater than 0.7 (Nunnally \& Bernstein, 1994). At this stage, VRS and CRS models in the forms of input and outputoriented are applied to rank the DMUs. Table 3 shows the results of DEA models.

The preferred DEA model is the one with maximum average efficiency value. According to Table 3, the preferred model is VRS output oriented, because this model has the largest value of efficiencies average in comparison to other three models. The results of sensitivity analysis are shown by Table 4, 
Table 5 and Fig. 3. Effect of resilience and ergonomics factors on system's efficiency reduction is investigated.

Table 3

Efficiency and rank of each DMU using different DEA models

\begin{tabular}{lcccccccc}
\hline & \multicolumn{4}{c}{ Efficiency } & \multicolumn{3}{c}{ Rank } \\
\cline { 2 - 10 } DMU & \multicolumn{2}{c}{ input- oriented } & Output-oriented & \multicolumn{2}{c}{ input- oriented } & \multicolumn{2}{c}{ output-oriented } \\
\cline { 2 - 10 } 1 & CRS & VRS & CRS & VRS & CRS & VRS & CRS & VRS \\
\hline 2 & 1.0573 & 1.0747 & 1.0573 & 1.0747 & 3 & 4 & 3 & 4 \\
3 & 1.0520 & 1.0574 & 1.0520 & 1.0574 & 5 & 6 & 5 & 6 \\
4 & 1.1466 & 1.1564 & 1.1466 & 1.1564 & 1 & 1 & 1 & 1 \\
5 & 1.0014 & 1.0662 & 1.0014 & 1.0662 & 20 & 5 & 20 & 5 \\
6 & 1.0446 & 1.0449 & 1.0446 & 1.0449 & 8 & 13 & 8 & 13 \\
7 & 1.0450 & 1.0516 & 1.0450 & 1.0516 & 7 & 10 & 7 & 10 \\
8 & 0.9929 & 0.9940 & 0.9929 & 0.9960 & 21 & 22 & 21 & 22 \\
9 & 1.0106 & 1.0419 & 1.0106 & 1.0419 & 18 & 14 & 18 & 14 \\
10 & 1.0391 & 1.0525 & 1.0391 & 1.0525 & 9 & 9 & 9 & 9 \\
11 & 1.0385 & 1.0392 & 1.0385 & 1.0396 & 10 & 16 & 10 & 16 \\
12 & 1.0345 & 1.0365 & 1.0345 & 1.0371 & 13 & 17 & 13 & 17 \\
13 & 1.0241 & 1.0310 & 1.0241 & 1.0313 & 15 & 19 & 15 & 19 \\
14 & 1.0954 & 1.0964 & 1.0954 & 1.0964 & 2 & 3 & 2 & 3 \\
15 & 1.0353 & 1.0350 & 1.0353 & 1.0358 & 12 & 18 & 12 & 18 \\
16 & 1.0146 & 1.0563 & 1.0146 & 1.0563 & 17 & 7 & 17 & 7 \\
17 & 1.0190 & 1.0510 & 1.0190 & 1.0510 & 16 & 11 & 16 & 11 \\
18 & 1.0077 & 1.0302 & 1.0077 & 1.0303 & 19 & 20 & 19 & 20 \\
19 & 1.0353 & 1.0403 & 1.0353 & 1.0403 & 11 & 15 & 11 & 15 \\
20 & 1.0532 & 1.0544 & 1.0532 & 1.0544 & 4 & 8 & 4 & 8 \\
21 & 0.9891 & 1.0001 & 0.9891 & 1.0001 & 22 & 21 & 22 & 21 \\
22 & 1.0459 & 1.0471 & 1.0459 & 1.0471 & 6 & 12 & 6 & 12 \\
\hline Average & 1.0322 & 1.1041 & 1.0322 & 1.1041 & 14 & 2 & 14 & 2 \\
\hline & $\mathbf{1 . 0 3 7 0}$ & $\mathbf{1 . 0 4 9 0}$ & $\mathbf{1 . 0 3 7 0}$ & $\mathbf{1 . 0 5 3 0}$ & - & - & - & - \\
\hline
\end{tabular}

Table 4

The importance of each input indicator in the case study

\begin{tabular}{llll}
\hline $\mathrm{X}_{1}$ & $\mathrm{X}_{2}$ & $\mathrm{X}_{3}$ & $\mathrm{X}_{4}$ \\
\hline 0.979 & 0.900 & 0.854 & 0.917 \\
\hline
\end{tabular}

Table 5

The importance of each output indicator in the case study

\begin{tabular}{llllllllll}
\hline $\mathrm{X}_{1}$ & $\mathrm{Y}_{2}$ & $\mathrm{Y}_{3}$ & $\mathrm{Y}_{4}$ & $\mathrm{Y}_{5}$ & $\mathrm{Y}_{6}$ & $\mathrm{Y}_{7}$ & $\mathrm{Y}_{8}$ & $\mathrm{Y}_{9}$ & $\mathrm{Y}_{10}$ \\
\hline 0.943 & 0.951 & 0.967 & 0.968 & 0.969 & 0.93 & 0.962 & 0.818 & 0.848 & 0.894 \\
\hline
\end{tabular}

In the proposed case study, "reliability" is the most important factor that could affect aerospace supply chain. Also, "Human resource management", "supplier's delay" and "availability" are among the most influential factors. Resilience engineering factors have satisfactory level which means managers and staff have enough knowledge about their job and they can assess and evaluate different situation properly (Plowman et al., 2007). 


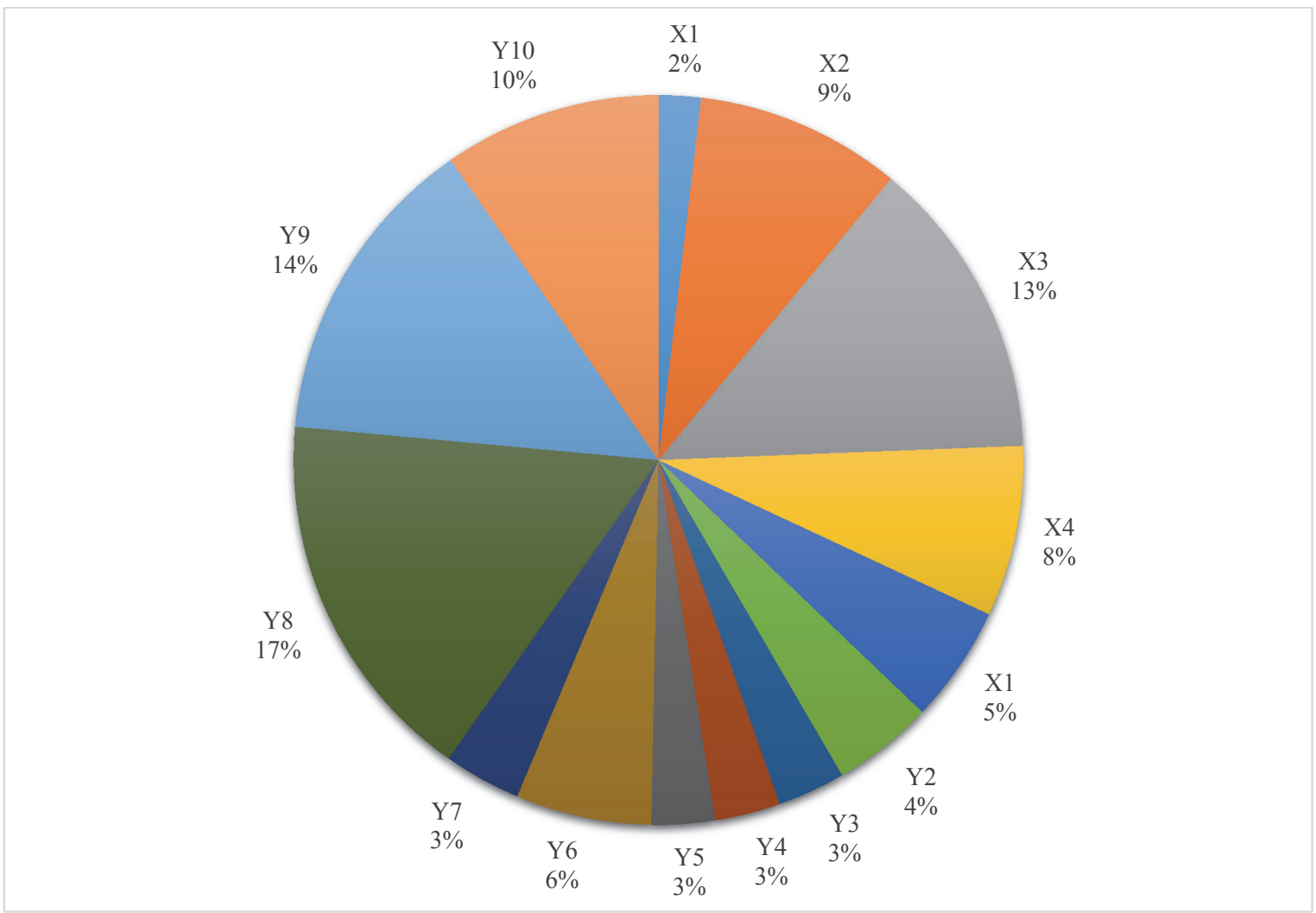

Fig. 3. The importance of each macro-ergonomics indicator in the case study

As stated before, the slack values could be explained as potential for improvement. This analysis determines the influential factors that would help managers to propose the proper strategies by focusing on influential factors. The slack value for each factor is presented by Table 6 .

Table 6

Potential values for improvement of input and output factors

\begin{tabular}{lccc}
\hline Factor & Potential improvement & Factor & Potential improvement \\
\hline $\mathrm{X}_{1}$ & 2.582 & $\mathrm{Y}_{4}$ & 1.167 \\
$\mathrm{X}_{2}$ & 0.000 & $\mathrm{Y}_{5}$ & 0.593 \\
$\mathrm{X}_{3}$ & 0.000 & $\mathrm{Y}_{6}$ & 0.612 \\
$\mathrm{X}_{4}$ & 0.023 & $\mathrm{Y}_{7}$ & 0.200 \\
$\mathrm{Y}_{1}$ & 0.052 & $\mathrm{Y}_{8}$ & 0.139 \\
$\mathrm{Y}_{2}$ & 0.528 & $\mathrm{Y}_{9}$ & 0.771 \\
$\mathrm{Y}_{3}$ & 0.023 & $\mathrm{Y}_{10}$ & 0.262 \\
\hline
\end{tabular}

According to the results, "lead time" has the most potential for improvement followed by preparedness and human resource management.

\section{Conclusions}

Aerospace supply chain is one of the most important divisions of this industry. This study proposed an integrated approach for assessing suppliers from resilience and ergonomics points of view. Impact of resilience and ergonomics factors on aerospace supply chain of an actual case study is also investigated. DEA has been used to find the preferred supplier as well as to distinguish the influential factors. According to the results of the case study "reliability", "Human resource management", "supplier's delay" and "availability" are among the most influential factors on aerospace supply chain. 
Furthermore, it is shown that "lead time" has the highest potential for improvement. The approach enables of aerospace decision makers to propose improvement plans to boost the supply chain taking into account resilience and ergonomics. In addition, strengths and weaknesses of supply chain and supplier selection process could be identified. For future studies, it would be interesting to introduce quantitative parameters to calculate the value of qualitative factors of this study. Using fuzzy DEA could also be applied to handle uncertain nature of qualitative approach.

\section{Acknowledgement}

The authors would like to thank the Editor-in-Chief of the "Uncertain Supply Chain Management" and anonymous reviewers for their helpful comments and suggestions, which greatly improved the presentation of this paper. Additionally, the authors would like to acknowledge the partially financial support of the Iran National Science Foundation under Grant No. 93034640.

\section{References}

Awasthi, A., Chauhan, S. S., \& Goyal, S. K. (2010). A fuzzy multicriteria approach for evaluating environmental performance of suppliers. International Journal of Production Economics, 126(2), 370-378.

Azadeh, A., Saberi, M., Rouzbahman, M., \& Saberi, Z. (2013). An intelligent algorithm for performance evaluation of job stress and HSE factors in petrochemical plants with noise and uncertainty. Journal of Loss Prevention in the Process Industries, 26(1), 140-152.

Azadeh, A., Salehi, V., Ashjari, B., \& Saberi, M. (2014). Performance evaluation of integrated resilience engineering factors by data envelopment analysis: The case of a petrochemical plant. Process Safety and Environmental Protection, 92(3), 231-241.

Banker, R. D., Cooper, W. W., Seiford, L. M., Thrall, R. M., \& Zhu, J. (2004). Returns to scale in different DEA models. European Journal of Operational Research, 154(2), 345-362.

Barnes, J., \& Liao, Y. (2012). The effect of individual, network, and collaborative competencies on the supply chain management system. International Journal of Production Economics, 140(2), 888899.

Burtscher, M. J., \& Manser, T. (2012). Team mental models and their potential to improve teamwork and safety: A review and implications for future research in healthcare. Safety Science, 50(5), 13441354.

Cardoso, S. R., Barbosa-Póvoa, A. P., Relvas, S., \& Novais, A. Q. (2015). Resilience metrics in the assessment of complex supply-chains performance operating under demand uncertainty. Omega, 56, 53-73.

Charnes, A., Cooper, W. W., \& Rhodes, E. (1978). Measuring the efficiency of decision making units. European journal of operational research, 2(6), 429-444.

Clegg, C. W. (2000). Sociotechnical principles for system design. Applied ergonomics, 31(5), 463-477.

Elleuch, H., Dafaoui, E., Elmhamedi, A., \& Chabchoub, H. (2016). Resilience and Vulnerability in Supply Chain: Literature review. IFAC-PapersOnLine, 49(12), 1448-1453.

Emiliani, M. L. (2004). Sourcing in the global aerospace supply chain using online reverse auctions. Industrial Marketing Management, 33(1), 65-72.

Fung, P. K., \& Chen, I. S. (2010). Human capital for supply chain management capabilities: a study of international trade intermediaries. International Journal of Logistics: Research and Applications, 13(1), 1-12.

Hale, A. R., \& Hovden, J. (1998). Management and culture: the third age of safety. A review of approaches to organizational aspects of safety, health and environment. Occupational Injury: Risk, Prevention and Intervention, 129-165. 
Harrison, A. (1999). Horses for courses: human aspects of different logistics systems. International Journal of Logistics: Research and Applications, 2(3), 247-261.

Hollnagel, E., Nemeth, C. P., \& Dekker, S. (Eds.). (2008). Resilience engineering perspectives: remaining sensitive to the possibility of failure (Vol. 1). Ashgate Publishing, Ltd..

Hollnagel, E., Woods, D. D., \& Leveson, N. (2007). Resilience engineering: Concepts and precepts. Ashgate Publishing, Ltd..

Jahanshahloo, G. R., Memariani, A., Lotfi, F. H., \& Rezai, H. Z. (2005). A note on some of DEA models and finding efficiency and complete ranking using common set of weights. Applied Mathematics and Computation, 166(2), 265-281.

Khan, M., Jaber, M. Y., \& Ahmad, A. R. (2014). An integrated supply chain model with errors in quality inspection and learning in production. Omega, 42(1), 16-24.

Kim, D. (2005, August). An integrated supply chain management system: a case study in healthcare sector. In International Conference on Electronic Commerce and Web Technologies (pp. 218-227). Springer Berlin Heidelberg.

Kim, Y., Chen, Y. S., \& Linderman, K. (2015). Supply network disruption and resilience: A network structural perspective. Journal of operations Management, 33, 43-59.

Koulikoff-Souviron, M., \& Harrison, A. (2006). Buyer-supplier relationships in inter-and intraorganisational supply contexts: the unobtrusive yet pervasive human resource picture. International Journal of Logistics: Research and Applications, 9(1), 75-94.

Nunnally, J.C., \& Bernstein, I.H. (1994). Psychometric Theory. McGraw-Hill, New York.

Paillé, P., \& Boiral, O. (2013). Pro-environmental behavior at work: construct validity and determinants. Journal of Environmental Psychology, 36, 118-128.

Pettit, T. J., Croxton, K. L., \& Fiksel, J. (2013). Ensuring supply chain resilience: development and implementation of an assessment tool. Journal of Business Logistics, 34(1), 46-76.

Plowman, D. A., Solansky, S., Beck, T. E., Baker, L., Kulkarni, M., \& Travis, D. V. (2007). The role of leadership in emergent, self-organization. The Leadership Quarterly, 18(4), 341-356.

Ponis, S. T., \& Koronis, E. (2012). Supply chain resilience: definition of concept and its formative elements. Journal of Applied Business Research, 28(5), 921.

Ponomarov, S. Y., \& Holcomb, M. C. (2009). Understanding the concept of supply chain resilience. The International Journal of Logistics Management, 20(1), 124-143.

Roshandel, J., Miri-Nargesi, S. S., \& Hatami-Shirkouhi, L. (2013). Evaluating and selecting the supplier in detergent production industry using hierarchical fuzzy TOPSIS. Applied mathematical modelling, 37(24), 10170-10181.

Serdarasan, S. (2013). A review of supply chain complexity drivers. Computers \& Industrial Engineering, 66(3), 533-540.

Sinclair, M. A., Siemieniuch, C. E., Cooper, K. A., \& Waddell, N. (1995). A discussion of simultaneous engineering and the manufacturing supply chain, from an ergonomics perspective. International Journal of Industrial Ergonomics, 16(4-6), 263-281.

Raj Sinha, P., Whitman, L. E., \& Malzahn, D. (2004). Methodology to mitigate supplier risk in an aerospace supply chain. Supply Chain Management: an international journal, 9(2), 154-168.

Vink, P., Koningsveld, E. A., \& Molenbroek, J. F. (2006). Positive outcomes of participatory ergonomics in terms of greater comfort and higher productivity. Applied ergonomics, 37(4), $537-$ 546.

Woods, D. D., \& Hollnagel, E. (2006). Prologue: resilience engineering concepts. Resilience engineering. Concepts and precepts, 1-16.

Yazdani, M. (2014). An integrated MCDM approach to green supplier selection. International Journal of Industrial Engineering Computations, 5(3), 443-458.

Ziaei, I., \& Sadeq Amalnick, M. (2015). Managing aerospace supply chain disruptions of "Outsourcing and Partnership", "Limited Buffers" and "Poor Planning and Execution". International Journal of Engineering Research and Management. 3(4), 223- 227. 
(C) 2017 by the authors; licensee Growing Science, Canada. This is an open access article distributed under the terms and conditions of the Creative Commons Attribution (CC-BY) license (http://creativecommons.org/licenses/by/4.0/). 